\title{
Understanding the micro-foundations of internal capabilities for open innovation in the minerals industry: a holistic sustainability perspective
}

\author{
Babak Ghassim*, Lene Foss \\ The School of Business and Economics, UiT-The Arctic University of Norway, Breivangvegen 23, 9010 Tromsø, Norway
}

\section{A R T I C L E I N F O}

\section{Keywords:}

Absorptive capacity

Sustainability

Open innovation

Minerals industry

Innovation capability

\begin{abstract}
A B S T R A C T
It is indisputable that achieving sustainability in the minerals industry requires a holistic approach to innovation that utilizes the breadth of knowledge found outside the industry. While providing a myriad of opportunities, this open approach to innovation would also be challenging in that companies need to have sufficient absorptive capacity, i.e. the ability to 'recognize', 'assimilate' and 'exploit' external knowledge when developing their processes and products. Despite recent theoretical advances, we do not yet fully understand the determinants of these three components of absorptive capacity for innovations aimed at sustainability. By employing a qualitative design with data obtained from 16 interviews conducted within Norway's minerals industry, this study explores the skills and routines that comprise micro-foundations of the capabilities for absorptive capacity. The analysis reveals that, in order to achieve recognition, companies need to firstly keep abreast of technological and market changes that emanate from sustainability transition, and secondly increase their awareness about social issues. Accordingly, assimilation depends on the established routines for facilitating dissemination of internal knowledge, whereas exploitation occurs by means of the piloting of innovative new solutions. This paper contributes to the sustainability-oriented innovation literature by demonstrating how companies in sustainabilitysensitive industries could benefit from various types of external knowledge in their innovation activities. It also provides some insights into the nature of open innovation and absorptive capacity beyond high-tech industries and research and development-based knowledge.
\end{abstract}

\section{Introduction}

The ever-increasing pressure on the global minerals industry ${ }^{1}$ to align sustainability and profit has raised the importance of a transition that includes the economic, environmental and social aspects of the business in this sector (Lei et al., 2013). Recent years have evidenced growing interest among policymakers and businesses regarding the key role that innovation plays in moving towards sustainability transitions, particularly in energy-intensive and environmentally sensitive businesses such as the minerals industry (OECD, 2011a; Smith et al., 2010; Song and Oh, 2015). In contrast to the limited outcomes from traditional approaches to innovation, an integrated sustainability-oriented innovation (SOI) allows companies to "make intentional changes to their products, processes or practices to serve the specific purpose of creating and realizing social and environmental value in addition to economic returns" (Adams et al., 2016, p. 180). By employing SOI, companies could address the environmental and social aspects of sustainability in a more proactive and strategic way, hence going beyond myopic practices such as pollution control and the reduction of social risks (Hart, 1995; Onkila, 2011). For example, responses to the imperative of reducing waste and pollution have shifted from just mandatory compliance with legal regulations to innovative actions such as creating value from waste and sustainability reporting (Bocken et al., 2014). In economic terms, whereas the mineral industry's margin from productivity advances and operational efficiency is shrinking, a broader approach to innovation could provide opportunities to meet new market demands from green industries and to gain social acceptance by creating new channels of interaction with societal stakeholders (Deloitte, 2016; Klewitz and Hansen, 2014; Nidumolu et al., 2009).

Research has shown that successful innovation requires organizational capabilities to build and reconfigure various types of knowledge resources (Rothaermel and Hess, 2007; Teece, 2007). Concurrently, sustainability transition signifies rapid changes in technologies, market demands, environmental regulations and social expectations (Lozano, 2015) which in turn require continuous modification in the knowledge base of firms (Teece, 2007). Moreover, tackling environmental and

\footnotetext{
* Corresponding author.

E-mail addresses: babak.ghassim@uit.no (B. Ghassim), lene.foss@uit.no (L. Foss).

${ }^{1}$ Following Upstill and Hall (2006), we define the minerals industry as 'companies engaged in exploration, extraction and primary processing of minerals'.
} 
social issues increases the necessity to understand the needs and impacts of a wide variety of stakeholders regarding innovation outcomes (Hall and Vredenburg, 2003; Sharma, 2005). To this end, companies are increasingly adopting open innovation, which is defined as "a distributed innovation process that involves purposively managed knowledge flows across the organizational boundary" (Chesbrough and Bogers, 2014). Examples in the mineral industry that evidence such an open approach to innovation are Anglo American's open collaboration forum (Waller, 2014), LKAB's joint venture with two equipment manufacturer for the development of remote monitoring technology (Westergren and Holmström, 2012), the involvement of local communities in gold mining in Central America (Erzurumlu and Erzurumlu, 2015) and the intensive collaboration regarding Elkem Solar Silicon (Ceccaroli and Tronstad, 2016).

As open innovation moves the locus of innovation outside organizational boundaries, innovation capabilities will depend on the absorptive capacity of firms, i.e. their ability to utilize externally acquired knowledge (Cohen and Levinthal, 1990; Lawson and Samson, 2001). We follow the definition of Lane et al. (2006) of absorptive capacity, which suggests a sequential process of 'recognize, assimilate and exploit' for building this capacity. In their view, prior knowledge of individual employees shapes the basis of understanding external knowledge, while integrating it with the existing knowledge base creates new knowledge outputs for developing innovations. Considering SOI, the diversity of external knowledge required to conduct process, product and social innovations necessitates various internal skills and routines in order to learn from a diverse range of external linkages (Adams et al., 2016). SOI-related capabilities are extensive and typically outside an individual firm's existing resource base (Lozano, 2007), especially when considering small mineral companies (Milanez and de Oliveira, 2013). Therefore, it is crucial for companies to identify skills and routines that underlie the different stages of recognizing, assimilating and exploiting different types of external knowledge.

Existing studies in this domain have not paid sufficient attention to the specificity of capabilities for innovation in sustainability contexts, particularly through a perspective that considers the comprehensiveness of SOI by taking into account all three aspects of sustainability transitions (Amui et al., 2017; Chen, 2016). For instance, Ayuso et al. (2006) proposed stakeholder dialogue and knowledge integration as the organizational capabilities required to absorb external knowledge, and introduced a set of structural and cultural mechanisms that facilitate the development of these capabilities. However, one caveat to this finding is the limited conceptualization of absorptive capacity that has led to other underlying mechanisms being ignored, such as employees' prior knowledge. In a quantitative study, Albort-Morant et al. (2016) used empirical data from the Spanish automotive industry to substantiate the fact that learning and integrating capabilities are important for success in environmental innovations. However, their standard measure of 'capability' may have handicapped their findings, as SOI capabilities are believed to differ from those for traditional innovations.

Considering the above, there is a need to enhance our knowledge of the specific skills and routines for undertaking SOI that help firms to move through the processes of recognizing, assimilating and exploiting external knowledge. Thus, this paper aims to answer the following research question: what are the capabilities, and their underlying skills and routines, that build the absorptive capacity required for SOI in the minerals industry? Accordingly, we use an exploratory case-study design (Yin, 2009), with data from 16 companies in Norway that form the empirical setting for this research.

By identifying the micro-foundations of capabilities (i.e. the underlying routines for building them) that are essential for SOI, this study contributes to the recent debate about how various (and somewhat conflicting) aspects of sustainability can be realized through internal and external learning mechanisms for innovation (Amui et al., 2017; Watson et al., 2017). Moreover, our fine-grained analysis of the determinants of absorptive capacity responds to the call for more research into the intra-organizational building blocks of this construct (Lewin et al., 2011). As scholars have paid scant attention to determinants beyond research and development (R\&D)-based knowledge (Vega-Jurado et al., 2008) or innovations with non-commercial purposes (Murphy et al., 2012), our empirical insights from the Norwegian minerals industry reveal some specific aspects of absorptive capacity when pursuing an innovation approach that entails both commercial benefits (for companies) and non-commercial benefits (for society).

The remainder of the paper is structured as follows: the next section provides an overview of the empirical setting; Section 3 describes the theoretical background; Section 4 deals with the research design and methodology; Section 5 presents the results of the case study; and Section 6 discusses the findings and implications.

\section{The empirical setting: Norway's minerals industry}

The Norwegian minerals industry produces a diverse range of minerals of various commodity types. The ore minerals sector dominated the industry until some decades ago, while industrial minerals, natural stone and construction minerals have gradually gained increasing importance in terms of employment and sales value. By production volume, Norway is among Europe's most important producers of olivine, nepheline, titanium minerals, iron ore, marble, quartz and flake graphite (Geological Survey of Norway, 2016). Furthermore, the country has promising potential for increasing the supply of minerals required for growth in green and high-tech industries such as renewable energy, the manufacturing of electric cars, electronics and aerospace.

Despite its historical presence, the size of the Norwegian minerals industry is quite small compared to other mineral-rich countries or the other domestic natural resource-based industries, such as oil and gas. In 2015 , the industry had $\approx 6000$ employees, distributed over 690 companies operating $\approx 1000$ mines and quarries. It had a turnover of roughly USD 1.55 billion (NOK 13.3 billion) in 2015, of which $>50 \%$ was from export markets. Even though the direct contribution of the minerals industry to Norway's gross domestic product (GDP) is very small ( $\approx 0.4 \%$ based on data from 2015 ), a recent analysis showed that the minerals value chain (considering manufacturing of mineral-based products, excluding oil and gas) contributes $12 \%$ of total GDP in Norway (The Science Park in Bodø, 2017). In addition, this industry has had a significant development effect in several peripheral regions of Norway, in terms of both direct employment and growth of local supplier industries (Smeds et al., 2016).

According to Siggelkow (2007), empirical settings for single-case research should provide a unique opportunity to obtain first-hand knowledge about the phenomenon under study. We consider that the Norwegian minerals industry, owing to some of its characteristics, makes an attractive case for a study of capability building and an open SOI approach. According to the Norwegian government's strategy for this industry, "efficient, socially responsible and environmentallyfriendly operation" should be at the core of development, and that new knowledge, cooperation and technological improvements should play an important role in realizing these intentions (Ministry of Trade and Industry, 2013). The openness of the economy and the relatively high proportion of small and medium-sized enterprises in the minerals industry - with a consequently limited internal knowledge base - will then favor a focus on externally oriented learning.

As shown in Table 1, addressing higher productivity growth and stricter environmental requirements by means of technological developments has led to a continuous improvement in key economic and environmental indicators. Moreover, while measures to ensure that companies act in a socially responsible way have yet to be developed, the government has exerted extra effort through the new Mineral Act to ensure the protection of nature-based activities related to herding and fish farming that are part of the livelihoods of the locals. Concerning market situations, geographical proximity to the European market and 
Table 1

Productivity, energy and emission intensities in the Norwegian minerals industry during 2013-16.

Source: Statistics Norway

\begin{tabular}{|c|c|c|c|c|}
\hline \multirow{2}{*}{ Indicator } & \multicolumn{4}{|l|}{ Year } \\
\hline & 2013 & 2014 & 2015 & 2016 \\
\hline Labor productivity (ktonnes/employee) & 15.60 & 16.14 & 17.59 & 20.91 \\
\hline Energy intensity (GWh/billion NOK income) & 154 & 133 & 122 & 112 \\
\hline $\begin{array}{l}\text { Emission intensity (ktonnes of } \mathrm{CO}_{2} \text { equivalent/ } \\
\text { billion NOK income) }\end{array}$ & 40.05 & 39.41 & 36.88 & 34.23 \\
\hline
\end{tabular}

access to a long coastline constitute competitive advantages for exportoriented mineral companies in Norway. In innovation terms, this has made knowledge exchange easier, especially in the case of linkages with process and manufacturing industries.

\section{Background and theoretical framework}

Following the OECD (2011b), sustainability transition denotes moving towards a form of industrial growth where triple-bottom-line objectives (i.e. social, environmental and economic) are taken into account. This multidimensional growth emphasizes the demand for innovative solutions that not only bring economic advantage, but also improve social well-being and decrease detriments to the natural environment (Smith et al., 2010). For the purpose of this paper, we define innovation as "the search for, and the discovery, experimentation, development, imitation and adoption of new products, new production processes and new organizational setups" (Dosi, 1988, p. 222). Accordingly, SOI comprises product, process and social innovations (Klewitz et al., 2014) that may originate either inside or outside a firm's boundary.

The following subsections provide the theoretical groundwork that directed our purpose to explore which internal capabilities the minerals industry should develop in order to pursue an open innovation approach in its SOI activities.

\subsection{The broadening scope of external learning linkages for SOI}

In recent decades, learning processes and innovations have increasingly become shared activities in industrial settings. Innovation is currently the result of interactions among various actors as components of an innovation system (Fagerberg et al., 2009). According to this open innovation paradigm, a company should be able to manage knowledge inflows and outflows across its boundaries (Chesbrough, 2003), yet the inward flow is more significant in non-high-tech settings such as the minerals industry (Bartos, 2007). In this respect, companies may gain access to external knowledge via two basic mechanisms, namely transactional and collaborative relationships (Greco et al., 2016); whereas the former implies monitoring the outside environment and/or sourcing technologies on a market basis, the latter represents active partnerships to develop new knowledge and innovation.

While companies can generally acquire knowledge from different external sources, a central topic in the literature has been to identify the main sources of knowledge inputs for innovation in different industries. A pioneering idea in this respect is the taxonomy provided by Pavitt (1984), which groups firms into three categories, namely supplierdominated, production-intensive and science-based. In Pavitt's view, the first category of firms is mainly dependent on the flow of knowledge from suppliers and, to a lesser degree, from large customers and research organizations, whereas engineering service providers and R\&D institutions are the essential knowledge providers for the second and third categories, respectively. In a similar vein, Asheim and Gertler (2005) make a distinction between industries with analytical and synthetic knowledge bases and go on to argue that firms in the first category draw substantially from basic science and knowledge produced in research organizations, while those with a synthetic knowledge base mostly interact with their suppliers and customers.

Regardless of different classifications, scholars seem to agree on a dependency between external knowledge sources and the type of knowledge they provide for innovation activities (i.e. technical, scientific, market, etc.). Existing studies suggest that companies rely on their suppliers to obtain technical knowledge related to process innovations, either in the form of knowledge embedded in technologies or by buying engineering services (Robertson et al., 2012). In the minerals industry, collaborative technology development projects could benefit both the mineral company and the equipment supplier by lessening the risk of failure, providing complementary access to financial resources and allowing the possibility of testing prototypes in a real operational setting (Lager et al., 2015). Moreover, managers in this industry are increasingly focusing on outsourcing their non-core activities (Morris et al., 2012), which could result in more flexibility in their linkages with suppliers compared with collaborative arrangements that require deep involvement and shared commitments.

As for knowledge about markets, existing customers and potential markets at large are the main sources of insight that drive innovative product solutions (Bogers and Lhuillery, 2011). Owing to the scarcity of mineral raw materials and their importance in global supply chains, manufacturing industries are reportedly concerned about relationships with their suppliers of raw materials (George et al., 2015). Moreover, interaction with raw-material suppliers is considered a crucial factor for the sustainability of product life cycles and ultimate market success. Pujari (2006) highlights the role of early-stage interaction with suppliers in maintaining a good reputation and increasing eco-efficiency and product quality. Not surprisingly, there is a shortage of research on such interactions from the perspective of the minerals industry. More attention to this shortfall is particularly important when considering the rise in the importance of rare earth and industrial minerals for applications in high-tech and renewable industries (Wang et al., 2017), which calls for an investigation of the dynamics of learning from (potential) customers for these mineral products.

Although not a main focus in non-high-tech sectors, innovationbased development in the minerals industry also requires the establishment of linkages with research organizations (Andersen et al., 2015). Industry-university interactions in such sectors create the applied knowledge required to address specific process- or product-related issues (Asheim et al., 2005). These interactions have proven beneficial for sustainable innovation through learning that happens via both formal collaborations, for example R\&D projects, and informal relationships between scientists and industrial personnel (De Marchi, 2012; Grimpe and Fier, 2010). The supply of human capital and engineering services from universities could also contribute to industrial development in mining regions (Figueiredo and Piana, 2016) which, among other positive consequences, would improve both the reputation and social responsibility of the companies concerned.

Beyond technical, market and scientific knowledge, the emerging literature on SOI points to the importance of societal stakeholders for innovation success, particularly those innovative outcomes that target social rather than commercial values. Drawing on several case studies in the UK, Holmes and Smart (2009) demonstrated the value of interacting with non-profit-making organizations as a source of knowledge on societal issues. Successful management of mining projects in the realm of stricter socio-environmental regulations is dependent on interactive communications with local stakeholders (Corder, 2015). This is in accordance with the results of a growing literature which draws on the concept of 'social license to operate' (Prno and Scott Slocombe, 2012) to argue that disregarding the interests and expectations of locals endangers both productivity and efficiency gains in this sector. Suopajärvi et al. (2016) conducted an in-depth empirical study to show that approaches towards social sustainability should go beyond reactive practices (such as the transparency of waste management activities) 
and further involve the community in the early stages of planning for mine development.

Nevertheless, the literature on external learning linkages to the minerals industry is rather sparse and is mainly focused on interactions with suppliers in user-producer relationships, which consequently do not reflect the industry's need for a broader approach towards innovation and sustainability. Our perspective in considering various types of knowledge relevant to SOI, including technical, market, scientific and social knowledge, and their respective external sources, could provide some insights into how firms respond to the broadening scope of learning linkages by developing their internal skills and competencies.

\subsection{Internal capabilities for absorbing external knowledge}

The above discussion suggests that various types of external knowledge sources are conducive to innovation, which may result in an expectation that learning and innovation are automatic results of exposure to an external environment. However, studies have found that these outcomes should not always be taken for granted. Instead, deliberate efforts and adequate amounts of 'internal' knowledge and competence are required to build the capacity for effective learning from these linkages (Zollo and Winter, 2002). This school of thought refers to a firm's absorptive capacity, a concept coined by Cohen and Levinthal (1990) and defined as the capability to utilize knowledge originating outside the firm. The term 'capability' is central to this conceptualization as it points to the 'dynamic' nature of absorptive capacity, which not only captures firms' resources (skills and knowledge competencies) but also their reconfiguration by means of organizational routines in order to comply with changes in the outside environment (Teece, 2007)

Since its introduction, absorptive capacity has undergone significant examinations regarding its definition, measurement and underlying processes. For the purpose of this paper, we follow recent contributions that have specifically advanced this construct by (1) developing a process-based view of it and (2) extending it beyond R\&D-based knowledge and commercial innovations. Regarding its definition and construct clarification, it is generally accepted that absorptive capacity is a multidimensional concept comprising three sequential processes: recognizing, assimilating and exploiting the external knowledge (Lane et al., 2006). Accordingly, our theoretical framework (Fig. 1) proposes that firms should develop recognition, assimilation and exploitation capabilities in order to convert external knowledge into different types of SOI, which are driven by various sustainability-related objectives.

Firstly, recognition capability enables a firm to identify and understand external knowledge resources. In the second step, assimilation provides the ability to integrate acquired and internal knowledge, which could result in only a slight change or in an entire transformation of the existing knowledge base (Todorova and Durisin, 2007). Finally, firms should be able to apply the new knowledge in their operations in order to improve performance.

Generally, firms use different routines for accumulation of these three capabilities, which depend to a large degree on the source of knowledge and its R\&D intensity. While early investigations relied on the R\&D activities of firms to examine their degree of absorptive capacity, there is growing support for the contribution of other types of skills and routines to this capacity (Bogers and Lhuillery, 2011; Vega-Jurado et al., 2008). Nevertheless, for technological changes in products and processes, R\&D activities play an important role in developing the scientific knowledge base of a firm and thereby improving the capability to exploit the external knowledge acquired from research-based organizations (Horbach, 2008). Besides R\&D, direct involvement in manufacturing processes and engineering activities can also trigger incremental innovations which, in most cases, can be applied to problem-solving strategies regarding specific product or process requirements (Hervas-Oliver et al., 2012). Similarly, Bogers and Lhuillery (2011) adopted a functional perspective to show that, in addition to R\&D, marketing- and manufacturing-related practices in a firm also absorb the relevant external knowledge required for product and process innovations.

At an intra-firm level, recognition and assimilation capabilities could also be enhanced by linkages between competitors or firms from different sectors within an industry. In this regard, both informal interactions via employee networks and formal collaborations in the form of strategic alliances have proved to be useful (Dantas and Bell, 2009; Madhok and Osegowitsch, 2000). Therefore, whereas R\&D activities lead to the creation of new knowledge, technological innovations also rely on capabilities beyond R\&D that are created by combinations of already existing knowledge by means of 'learning by doing and using' (Jensen et al., 2007).

On the other hand, non-commercial innovations in terms of improvements in social practices call for an absorptive capacity that differs in terms of its underlying skills and routines. Murphy et al. (2012) delineate that, in the case of external linkages with societal stakeholders, fundamental differences between the expectations of businesses and locals lead to large learning gaps that should be bridged by effective communications. In another study of the absorptive capacity for social innovations, Veldhuizen et al. (2013) maintained that an open culture, employee involvement and an hierarchical structure drive effective dialogue and knowledge integration for sustainable innovations.

The above review reveals the lack of a thorough, fine-grained understanding of recognition, assimilation and exploitation capabilities for SOI. This informs our objective to explore the skills and routines that shape these capabilities.

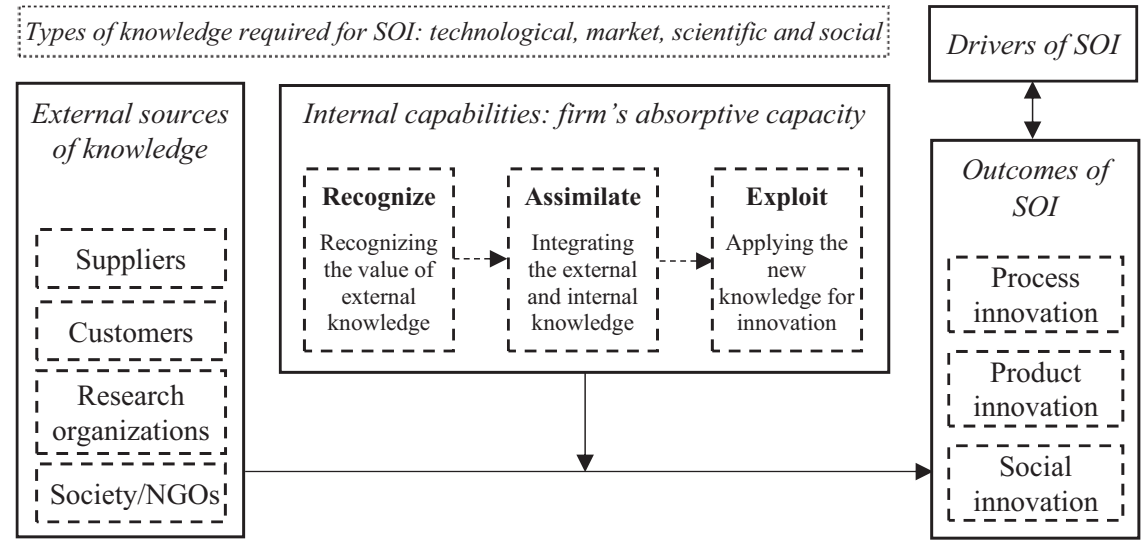

Fig. 1. Theoretical framework. Illustration by the authors according to Lane et al. (2006). 


\section{Research design and methodology}

To answer the research question, we adopted an abductive qualitative approach that is appropriate for elaborating on existing theories where "gaps or oversights need to be filled in" (Pratt, 2009, p. 859). Considering our research question, while the literature argues for the necessity of recognition, assimilation and exploitation capabilities, the mechanisms through which these capabilities unfold in the context of SOI have yet to be thoroughly specified. Thus, our use of abductive reasoning in this paper is that we start from the general theory of absorptive capacity, hence drawing on our empirical insights to recontextualize this theory in relation to the different capabilities for SOI. Accordingly, an embedded single-case design (Yin, 2009) is used to study various mineral companies as the subunit for our eventual unit of analysis (the industry). This allows the industry to be maintained as the target of the study for exploring the accumulation of capabilities, while at the same time investigating the micro-foundations of these capabilities at firm level by doing a comparative analysis among the companies. Regarding the subunit of analysis (embedded companies), we employed a theoretical sampling strategy (Emmel, 2013) to select cases that could provide in-depth knowledge of the phenomenon under study. Insight derived from reviewing available documents such as industry analyses and annual reports was combined with observations made at the annual meeting of the industry to select companies with certain degrees of internal and external innovation activities. We deliberately took into account a variety of cases in terms of sectors and geographical locations in Norway. Consequently, a list of 22 potential sample cases was prepared, of which 16 companies agreed to participate in our research.

The informants in this study have an executive responsibility for innovation activities in their respective companies. The aim is to capture data via people who are embedded in the phenomenon (Gioia et al., 2013), with the intention that their experience-based interpretations can provide knowledge of the characteristics of capabilities and innovation practices in their companies. None of the authors knew the informants beforehand, and nor did they have any relationships or engagement with the companies. To collect the required data, we prepared a list of questions that revolved around drivers of innovation, various knowledge-exchange mechanisms and internal processes for building innovation capabilities. We deliberately did not use the term 'sustainability' during the interviews to avoid potential social desirability bias. This list of questions, together with a procedural explanation of the data collection, led to the development of an interview protocol (see Appendix A) that supports the reliability (replicability) of our research (Yin, 2009). The first author conducted the interviews via Skype, which enabled a close face-to-face connection with the informants, regardless of their geographic dispersal (Deakin and Wakefield, 2014). The interviews lasted on average one and a half hours, and were conducted during a 6-month period in 2016.

All the interviews were recorded and transcribed, and totaled 220 pages of single-spaced text. We used the NVivo software package to carry out the analysis in three main phases, i.e. coding, classification and cross-tabulation. Based on the principles of inductive thematic analysis (Gioia et al., 2013), we followed a consecutive and recursive process of coding and classification. Firstly, the authors read the data independently and looked for concepts and expressions related to sustainability drivers, different types of SOI, internal capabilities and external sources of knowledge. This first-order analysis led to the identification of 86 distinct concepts. In the second phase, we discussed the similarities and differences between these concepts across the cases in order to classify them under fewer themes, which left us with 27 distinct groups, which we called second-order themes. Then, after several recursive processes of consultation with the existing literature, these themes were reduced to seven ultimate constructs. In the third and final phase of the analysis, the relationship between the emerged constructs was tabulated in a co-occurrence matrix, which indicates pieces of data that receive two specific codes. This matrix has the advantage of providing both qualitative and quantitative (i.e. how many times a co-occurrence is evidenced) insights, allowing us to look for patterns that link SOI types with drivers of sustainability, external linkages and internal capabilities. Appendix B presents an example section of the data structure to illustrate the emergence of ultimate constructs from firstorder codes, together with an overview of the second-order themes.

In order to establish the credibility of our findings, we considered two strategies to check for construct and external validity (Yin, 2009). Firstly, the transcripts were sent to the interviewees to obtain their feedback and further reflections. When available, the interview data were triangulated with other information from each company (such as annual reports, news and data from conference presentations and internet documents) to check the consistency of the data. In the case of inconsistencies, we asked the informants for clarifications and comments concerning specific points. Secondly, the multiple cases embedded in our holistic case enabled us to apply replication logic (Yin, 2009 , p. 54) by means of looking for similar (literal replication) and contrasting (theoretical replication) results across our cases, thereby increasing the generalizability of our findings to other similar contexts.

\section{Findings}

\subsection{Descriptive case findings}

The companies in our study belong to the four main sectors of the minerals industry in Norway, namely construction minerals, metallic ores, industrial minerals and natural/dimension stones. Among these 16 companies, five are large, six are medium-sized, four are small and one is a micro-enterprise. ${ }^{2}$ For reasons of confidentiality, the original names of the companies were changed to the letters A-P and are referred to by these letters throughout the paper. Appendix $C$ presents an overview of the case companies and interviewees.

As shown in Appendix B, the outputs from NVivo provide some descriptive statistics of the data, including the number of times that a specific concept or expression appeared in the transcribed interviews. Considering the different types of SOI in the minerals industry, process innovations seem to be more prevalent (being mentioned 70 times by the interviewees), followed by product and social innovations (58 and 37 references, respectively). Our results indicate that suppliers and research organizations are the most frequent external sources of knowledge used in the Norwegian minerals industry, while companies have yet to establish appropriate mechanisms for gaining knowledge from their societal stakeholders and customers. These external linkages represent a diversity of networks in terms of geographical location, ranging from local societal stakeholders to those that cross national boundaries. Interestingly, the results evidence that local and international networks are used equivalently, which in turn points to the fact that the knowledge required for SOI is geographically dispersed.

In the following, the case study results are presented in three sections based on the related sets of final constructs that emerged from the coding process. The first set demonstrates the link between drivers of SOI activities and their outcomes; the second set discusses the characteristics of linkages with external knowledge sources; and the third section synthesizes the findings around processes for developing absorptive capacity.

\subsection{What are the drivers and outcomes of SOI activities in the minerals industry?}

Norwegian mineral companies are primarily concerned with innovating within their extraction and production operations. These

\footnotetext{
${ }^{2}$ Micro, small and medium-sized companies are those with fewer than 10, 50 and 250 employees, respectively (European Commission, 2012).
} 
Table 2

Illustrative quotes regarding the characteristics of external linkages.

\begin{tabular}{|c|c|c|c|}
\hline Knowledge source & Acquisition mechanisms & Geographical breadth & Illustrative quotes \\
\hline Suppliers & $\begin{array}{l}\text { Transactional (purchase of machinery, } \\
\text { contracting out technical services) } \\
\text { Collaborative (technology development } \\
\text { projects) }\end{array}$ & $\begin{array}{l}\text { Mostly within Scandinavia/ } \\
\text { European Union }\end{array}$ & $\begin{array}{l}\text { "There is a certain supply of equipment from Scandinavian players, } \\
\text { I mean both Sweden and Finland, that have a strong supplier sector } \\
\text { for the mining industry which are quite front end-oriented and } \\
\text { innovative in many ways." (Company N) } \\
\text { "Collaboration [with technology suppliers] is not common, with } \\
\text { some exceptions for example (...) because they needed data about } \\
\text { the metallurgical properties of our raw material to develop their } \\
\text { washing equipment." (Company E) }\end{array}$ \\
\hline Customers & $\begin{array}{l}\text { Transactional (monitoring the markets, } \\
\text { conferences, on-site visits) } \\
\text { - Collaborative (product development projects) }\end{array}$ & $\begin{array}{l}\text { Varied, depending on the } \\
\text { target market }\end{array}$ & $\begin{array}{l}\text { "I'm actively taking part in international conferences, so we have a } \\
\text { general clue about what is happening in our potential markets and } \\
\text { their demand." (Company A) } \\
\text { "I think the development of our X product fits very well with the } \\
\text { definition of a collaborative relationship as we were in close } \\
\text { collaboration with the solar cell manufacturers from the start of } \\
\text { that project." (Company J) }\end{array}$ \\
\hline $\begin{array}{l}\text { Universities/research } \\
\text { institutes }\end{array}$ & $\begin{array}{l}\text { Transactional (outsourcing R\&D services, } \\
\text { personal contacts with researchers) } \\
\text { - Collaborative (R\&D projects) }\end{array}$ & Mostly nationally focused & $\begin{array}{l}\text { "We initiated mineral exploration in a very unconventional area } \\
\text { where we have collaborators from NTNU and a university in } \\
\text { Denmark." (Company B) } \\
\text { "At the meetings organized by the industry cluster, people from the } \\
\text { research organizations share their knowledge about specific issues } \\
\text { of interest for the industry." (Company J) }\end{array}$ \\
\hline Society/NGOs & $\begin{array}{l}\text { - Collaborative (open meetings with the locals, } \\
\text { dialogue with NGOs, form expert groups from } \\
\text { local businesses) }\end{array}$ & $\begin{array}{l}\text { Local but in some complex } \\
\text { cases extending to national } \\
\text { scope }\end{array}$ & $\begin{array}{l}\text { "Before making final decisions, we found and involved those } \\
\text { people who were more willing to be engaged and then organized } \\
\text { them in several groups to take care of some of the development } \\
\text { requirements." (Company P) } \\
\text { "We are aware that it will not be enough if the knowledge only goes } \\
\text { one way, for example only by distributing some reports." } \\
\text { (Company I) }\end{array}$ \\
\hline
\end{tabular}

process innovations usually occur in the form of utilizing new technologies and making continuous incremental improvements to existing equipment or processes. While such improvements have been important due to the quest for cost-cutting, pressure from environmental regulations made it inevitable that advanced technologies would be employed. According to case $\mathrm{L}$ :

“(...) so the further development in this industry relies on production processes that are able to increase the yield, decrease the waste materials and pollutants, and make progress in energy efficiency."

The above quote signifies a trend in the sample that suggests the existence of three main drivers for process innovations in this industry: reducing emissions and waste; increasing productivity; and improving energy efficiency. Productivity enhancement, which includes factors such as labor, resource and capital, has always been at the top of the agenda for managers in this industry. In Norway, the existence of an attractive oil and gas sector that attracts a large share of funding opportunities, as well as high labor costs, intensifies the importance of productivity for economic sustainability. On the other hand, waste/ pollution reduction and energy-efficient strategies are mostly directed towards environmental sustainability through either end-of-pipe solutions such as utilizing water treatment equipment or more proactive and strategic practices, including recovery/reuse processes and the employment of clean technologies.

While the industry is mostly concerned with process improvements, the interview data show that two objectives motivate the companies to undertake product innovations: increasing the quality (purity) of their raw-material products; and finding new applications for the minerals. As the chief executive officer (CEO) of company G remarked:

"The idea in our company as our survival strategy was to look into the different ore minerals and investigate what kinds of special applications could be developed for those minerals."

Moreover, the R\&D manager of company $\mathrm{J}$ explained what forces them to focus not only on process improvements, but also on new- product developments:

“(...) there will be then an increased demand for highly purified minerals that are absolutely necessary for production of more sustainable solutions for power production, electric cars, windmills, etc. And to achieve our objectives in product development projects, changes in machinery and enrichment processes are required."

Tougher competition in the market for raw materials, especially in the metallic ore and industrial minerals sectors, has urged companies to invest in developing specialized products for niche markets. For example, one company in our sample is involved in developing an entirely new product that can assist in removing nuclear pollutants. In this way, the company will be able to bring environmental value to society while ensuring its competitive advantage in a rather saturated market for standard products.

Besides innovative outcomes in processes and products, we found an increasing awareness about societal issues which, in turn, led to the creation of a third innovation path, i.e. social innovation. As stated by the CEO of company D, whereas creating a better social profile could be achieved as a by-product of improvements in areas such as pollution control, the increasing power of interest organizations requires additional efforts with clearer contributions to social well-being:

"During several interactions with stakeholders, we have learned that the community around our mine expects us to provide more jobs in the region. This is now one of our highest priorities that can strengthen our tie with them."

We conclude that there is a necessity to ensure a 'social license to operate' in order to achieve sustainability in this industry, because insufficiency of social practices might result in having to cease or delay operations at the mine. Therefore, social innovations could enable the minerals industry to obtain social approval as an essential component of their long-term economic sustainability strategy. 


\subsection{What characterizes external-learning linkages for minerals sustainability?}

All the firms in our study had some experience of incorporating external sources in their innovation processes, including suppliers, customers, research organizations and local communities/interest organizations. As depicted in our theoretical framework, we distinguish between these linkages in terms of their knowledge content, i.e. technical, scientific, market and social knowledge. The case study shows that such a variation resulted in using different mechanisms for acquiring external knowledge, as well as reconciling the geographical scope of the knowledge search. Table 2 presents some example quotes to illustrate the knowledge acquisition mechanisms and the geographical breadth of external linkages with the four aforementioned knowledge sources.

In Norway, and as far as our sample represents, linkages between the mineral companies and their suppliers occur mostly on a transactional basis, in the form of buying machinery and technical services. Choosing the right suppliers appears to be particularly appropriate as it enables the mineral companies to gain access to the high-quality knowledge embedded in efficient/clean technologies and/or people. To maximize the benefit from such learning, a firm should exhibit a specific level of internal knowledge that is necessary for implementing and customizing the technologies. Indeed, we found that buying ready-touse technologies is becoming less common as greater interaction between equipment suppliers and mineral companies (users of technologies) is needed during customization of the final solutions:

"When we need equipment, we usually refer to our selected suppliers that are located wherever in the EU. So they come back to us with their offers

(...) then we enter into a contract to customize the equipment based on our specific requirements."

When necessary, relationships with suppliers may turn out to be highly collaborative. The main logic behind collaborative arrangements is to ensure the mutual flow of knowledge between the mineral companies and their suppliers, which in turn emanates from the complexity of knowledge required to develop the final process solution. For instance, in the case of company E (see Table 2), the unconventionality of the raw material has made it inevitable for the company to collaborate closely with its washing equipment supplier and to provide them with access to operational data over a relatively long period. The complexity aspect of knowledge also resonates by broadening the geographical scope of linkages with suppliers, as the need for advanced technological solutions and expertise increases the importance of being aware of global actors and their offerings. Although geographical distance may decrease the ease of knowledge flow, the existence of institutional frameworks such as trust-based culture and policies for promoting partnerships could remove some of the obstacles. As remarked by several companies in our study, closely related cultures and the existence of policy initiatives for nurturing collaboration in the Nordic region are decisive factors for the flow of technology and knowledge from Sweden and Finland, which are the homes of strong supplier industries.

"I would say that they [our relationships with suppliers] are more often regional, and by region, I'm thinking about Scandinavia. Sometimes we have contacts in other countries (...) but the point with the Scandinavian partners is that we easily trust each other." - Company $H$

While doing business in such a globalized industry does not allow for price competition, the majority of our cases showed their increasing interest in monitoring market changes and product innovations. In most cases, the person responsible for the marketing activities of the company was evidenced to be in charge of monitoring the markets, particularly those in high-tech and/or renewable energy industries. In smaller companies, the CEO plays this gatekeeper role, whereas in larger ones the sales manager/market developer is the one who tries to ensure that the relevant market knowledge is transmitted to the company. Nevertheless, developing radical products pushes downstream linkages to be more collaborative, instead of just a one-way knowledge flow to the mineral companies. This radical nature relates to an entirely new application (e.g. the development of a mineral product for remediation of radioactive waste from the sea) or to advanced technical knowledge (e.g. producing crack-free and low-emission concrete). As noted by company C:

"We collaborate a lot with concrete producers. Especially with one of them, we are combining our technical expertise and production em-

ployees in order to find out the best possible way to make good concrete."

The findings on the geographical breadth of downstream linkages show notable variance among companies in the minerals industry. On some occasions, especially in the case of industrial minerals, the knowledge-exchange process occurs in a broadly international domain. This is also the case for complex and radical innovation projects. In contrast, in the case of construction minerals, the physical characteristics of which are to a large extent location-dependent, companies look for market knowledge from customers in their vicinity. Moreover, as customers tend to consider the sustainability of a product's life cycle from the very beginning, it is important to involve them in product development projects at an early stage.

Norwegian research organizations have traditionally played a significant role in creating the scientific competencies required for developing the country's resource-based industries (Fagerberg et al., 2009). As expected, little internal R\&D activity in the minerals industry is compensated for by outsourcing the production of scientific knowledge to competent institutions and universities. The Norwegian University of Science and Technology (NTNU) and the Foundation for Scientific and Industrial Research (SINTEF) are the most significant players in this regard. In some cases, mineral companies had some experience of being engaged in collaborative and publicly funded research projects led by a big research organization such as SINTEF or NTNU. However, involvement in large projects requires more internal resources (both financial and human) and trust, and hence the lack of any of these factors could result in a preference for dyadic relationships (i.e. those between a single company and a research organization) rather than those that involve other companies and research organizations.

"When we collaborate with a research institution, we share proprietary information about our processes or products. When other companies are a part of a project, we are afraid of losing this information to our competitors." - Company $O$

The data signify that the minerals industry is mostly nationally oriented when it comes to scientific linkages. Indeed, the presence of a globally competitive process industry (in terms of both cleanliness and productivity) in Norway has led to the development of strong research groups within the universities/R\&D institutes that leverage their internal skills and external networks to supply a large share of the required knowledge in the minerals industry. Nevertheless, in a couple of cases where the aim was to develop advanced products or to undertake patent-driven research, mineral companies opted to involve foreign research organizations. Interestingly, even in these cases, a Norwegian research organization was also part of the collaboration, in order to ease the acquisition and further application of the scientific knowledge.

Our case study also sheds some light on the characteristics of linkages with societal stakeholders. Firstly, we found evidence to argue that companies are incrementally moving towards collaborative knowledge exchange, using mechanisms such as dialogue with interest organizations (e.g. environmental non-governmental organizations [NGOs]) about their environmental impact, which could consequently lead to remedial actions within the operations. Secondly, the degree of organizational involvement is increasing as companies are trying to incorporate knowledge about social issues into various organizational levels and functions in order to address the complexity of absorbing this 
type of knowledge. Following the CEO of company B:

"Obtaining [social] information is expensive. I don't mean monetary value, but the amount of time and engagement that should be spent. When we want to discuss with the communities, a team including managers, consultants and production engineers has to show up."

Thirdly, social linkages are found to be geographically limited to where the mine or processing plant is located. This is due to the high local impact of the minerals industry, both in a positive (regional development) and negative (socio-environmental impact) manner. Moreover, social knowledge is mostly intuitive (e.g. the expectations of locals) and based on context-specific experience (e.g. nature-based activities such as fishing or reindeer husbandry) that adds to its tacitness and the difficulty of assimilation. Therefore, geographical proximity to the external sources of social knowledge could assist mineral companies in converting the relevant knowledge into innovative outcomes.

\subsection{What capabilities underlie the absorptive capacity for SOI?}

Considering the findings presented in Sections 5.2 and 5.3, mineral companies exhibit capabilities that absorb various types of external knowledge (technical, scientific, market and social) in order to practice process, product and social innovations. As the process perspective on absorptive capacity illustrates (see Fig. 1), these capabilities can be categorized under recognition, assimilation and exploitation processes. Our data suggest that four types of capabilities underlie these processes: (1) keeping abreast of changes in technologies and markets; (2) increasing awareness about social issues; (3) facilitating internal knowledge dissemination; and (4) piloting new, innovative solutions. While the first two capabilities focus on identifying and understanding external knowledge (recognition), the third and fourth lay the foundations for integrating it with prior knowledge (assimilation) and applying the resultant new knowledge for innovative purposes (exploitation), respectively. Table 3 summarizes the findings regarding these capabilities and their micro-foundations (underlying skills and routines).

With regard to recognition, mineral companies seem to require a specific degree of prior knowledge on related technologies and markets to locate and understand the external knowledge. To follow up the continuous changes in what the potential markets for minerals perceive as sustainable solutions, some cases in our study referred to practices such as participation in conferences, which is not only a knowledge source in itself, but also an arena enabling them to identify other sources of knowledge by means of networking. On these occasions, the market knowledge accrued by the company acts as a facilitator for future knowledge acquisition through the existing network. Moreover, keeping abreast of changes in technologies and markets necessitates an ability to employ the relevant staff and train them on a regular basis. Our case study shows that understanding the knowledge embodied in technologies plays a central role in innovation activities in this industry. The proper operation of equipment requires a substantial level of prior experience at the individual-employee level that is not available based on existing skills or via user manuals/general instructions. Therefore, companies opt to recruit technicians who, through their earlier careers have the practical skills to work with specific equipment. In cases where some prior knowledge exists, training and continuing education seem to be more prevalent due to the high cost of labor in Norway. On-the-job training has been found to be particularly important for familiarizing staff about the incremental technology developments regarding waste reduction and recycling processes. As noted by company I:

"The main reason [to educate employees] has been to adjust our production processes according to the environmental regulations since they are sometimes changing overnight."

The recognition component of absorptive capacity in our case study demonstrates a specific capability for understanding external social knowledge, referred to here as awareness about social issues. In this regard, we found that acquiring social knowledge relies primarily on the managers' desire to act ethically. This desire is a decisive factor for establishing a positive reputation in local communities, which consequently makes them willing to share their knowledge with the mineral companies. In contrast, as noted by company $\mathrm{H}$, companies that only respond to coercive forces (e.g. pressure from the government) are often perceived by societal stakeholders as possessing a lack of responsibility, thereby losing the opportunity to build trust-based relationships and gain access to the valuable knowledge required for continuous improvements in social sustainability.

"These [environmental] rules are quite strict in Norway and the government forces us to follow the best practices for tailings disposal (...) but here the challenge is to get the locals to trust in us and collaborate with us."

Table 3

Illustrative quotes about the micro-foundations of capabilities for building absorptive capacity.

\begin{tabular}{|c|c|c|}
\hline \multicolumn{2}{|c|}{ Identified capabilities and micro-foundations } & $\begin{array}{l}\text { Excerpts from the interviews } \\
\text { "(...) recruited from northern parts of Sweden and Finland since we purchased new equipment from } \\
\text { suppliers in those countries" (Company D) }\end{array}$ \\
\hline Recognition & $\begin{array}{l}\text { (1) Keeping abreast of changes in technologies and } \\
\text { markets } \\
\text { - Prior knowledge base } \\
\text { - Recruiting new technicians and university graduates } \\
\text { - Employee training and continuing education } \\
\text { (2) Increasing awareness about social issues } \\
\text { - Managers' desire to act ethically } \\
\text { - Setting specific objectives for responding to social issues }\end{array}$ & $\begin{array}{l}\text { "(...) recruited from northern parts of Sweden and Finland since we purchased new equipment from } \\
\text { suppliers in those countries" (Company D) } \\
\text { "Cooperation with technical colleges for training our employees is helping us to secure the need for } \\
\text { competence" (Company C) } \\
\text { "(..) achieving success when the managers had a passion for resolving social conflicts" (Company K) } \\
\text { "(..) the corporate social responsibility (CSR) projects were truly small, so we had to be quite } \\
\text { realistic about the target and be specific on the required information to meet those targets" } \\
\text { (Company I - regional manager) }\end{array}$ \\
\hline Assimilation & $\begin{array}{l}\text { (3) Facilitating internal knowledge dissemination } \\
\text { - Sharing experiences among co-workers in a specific unit/ } \\
\text { function } \\
\text { - Intra-firm communication channels across technical, } \\
\text { market and social knowledge bases }\end{array}$ & $\begin{array}{l}\text { "(...) promoted communication inside the company in such a way that it became part of the } \\
\text { organizational culture" (Company D) } \\
\text { "To ensure knowledge sharing among more than one plant, we expect the unit managers to arrange } \\
\text { meetings to find a solution" (Company F) } \\
\text { "To modify our product, we should fully understand a customer's desired specifications for the } \\
\text { product, (...) and this knowledge is not something that our marketing people have. Then (...) discuss } \\
\text { it internally within the production and R\&D departments" (Company G) }\end{array}$ \\
\hline Exploitation & $\begin{array}{l}\text { (4) Piloting new innovative solutions } \\
\text { - Experimentation and testing process-related changes } \\
\text { - Piloting new products and socially related practices on a } \\
\text { small scale } \\
\text { - Maintaining external relationships to receive appropriate } \\
\text { feedback }\end{array}$ & $\begin{array}{l}\text { "In these changes [on the machinery], the employees' knowledge about our minerals and processes is } \\
\text { essential to experiment [with] what works and what doesn't work" (Company L) } \\
\text { "(...) to decrease the rest materials by implementing a new technique for drilling and blasting (...), } \\
\text { but we had to check with one of our customers first to see whether they are satisfied with the new } \\
\text { product" (Company M) } \\
\text { "After publishing our first sustainability report, we recognized through our meetings with } \\
\text { environmental activists that caring about the employees' safety is something that might capture their } \\
\text { interest. Then we used this insight in our future communications with them" (Company B) }\end{array}$ \\
\hline
\end{tabular}


The desire to act in accordance with social expectations is then combined with the capability to set specific social objectives, as the complexity of environmental and social issues might hinder companies for approaching them at the right time (i.e. prioritizing daily operations due to the lack of sufficient time and financial resources). As seen in cases I and O, breaking down complex issues into specific targets and communicating those targets to the societal stakeholders helped the companies to identify experts or interest organizations as potential sources of social knowledge.

Concerning assimilation, the findings suggest that internal knowledge dissemination, both within and across different units/functions, is required to integrate external knowledge with existing skills and abilities. To ensure this integration, some cases in our sample have managed to reach such a level of maturity in internal communication that knowledge sharing became part of their organizational culture. Arranging periodic meetings and encouraging peer-to-peer interactions are perceived to be fundamental parts of assimilation, as a great deal of knowledge about technologies, markets and social issues is tacit and cannot flow easily without face-to-face communications. More interestingly, as pointed out by cases B and $\mathrm{N}$, the necessity for involvement of various functions in the assimilation processes is likely to increase across the spectrum from technological to social knowledge. That is, in order to integrate external market knowledge, technical staff from production and $\mathrm{R} \& \mathrm{D}$ functions should also be involved, as well as those responsible for marketing activities, and for social knowledge, in addition to the above, those in charge of communication with societal stakeholders should also be engaged.

"Our systematic view to information from locals or voluntary agencies gives us a good way of improving and making more sense from them (...) they speak a different language that is not easy to understand (...) so different people work together in organized teams." - Company $N$

In this respect, knowledge-sharing processes that happen between firms are also crucial. For instance, companies that use similar machinery and technical processes - such as those involved in the metallic ore and industrial minerals sectors - noticed a benefit from sharing their experiences, which in turn resulted in assimilation at an inter-firm (industry) level. Nevertheless, coordinating inter-firm knowledge sharing seems to be challenging for individual companies, and this is where intermediary organizations such as the Mineral Cluster Norway ${ }^{3}$ and the Association of Norwegian Mineral Industry ${ }^{4}$ are crucial in providing such opportunities.

"We are a member of a technical committee in the industry association (...) once we talked about our problems with equipment. This is a problem for the whole industry (...) so our aggregates were used as a case and we get good ideas from other companies." - Company $E$

Finally, insights into how companies exploit knowledge resulting from assimilation processes support the existence of three interrelated capabilities: experimentation, small-scale testing and the maintenance of external relationships. As reflected in the quote from case $\mathrm{L}$ in Table 3, experimentation represents utilizing a combination of knowledge, particularly on technical solutions, for the purpose of trial and error and incremental changes. In such cases, knowledge gained from elsewhere (training, co-workers, etc.) is combined with prior experiences for further 'learning by doing' and the achievement of innovative outcomes. Similarly, we evidenced that successful product and social innovations need to be tested by users and stakeholders on a small scale, before implementation in larger projects and markets. As noted by the companies themselves, addressing sustainability often entails some trade-off between its different aspects, which in turn necessitates testing an innovative solution before final development and implementation.

\footnotetext{
${ }^{3}$ http://www.mineralklyngenorge.no.

${ }^{4}$ https://www.norskbergindustri.no/about-us-info-in-english/.
}

For instance, achieving a lower environmental footprint may come at the expense of lower product quality (e.g. the durability of a natural stone) and challenges with regard to satisfying customers. Therefore, as the third capability for exploitation depicts, successful exploitation requires the ability to retain external linkages up to the point that the desired commercial or non-commercial (e.g. social) value is created. This capability serves as a feedback loop from the exploitation step to the acquisition of new knowledge from external sources.

\section{Discussions}

\subsection{Discussion of findings}

This qualitative study adopted a process view of absorptive capacity to explore the capabilities for recognition, assimilation and exploitation of external knowledge in order to undertake SOI activities. More specifically, attention was directed towards capabilities for pursuing a broad innovation approach, where learning from various external knowledge sources is necessary for economic, environmental and social sustainability. To this end, we demonstrated the knowledge characteristics that condition the use of knowledge-acquisition mechanisms, and revealed a set of skills and routines that contribute to the development of certain capabilities for absorbing the acquired knowledge.

Regarding the mechanisms for knowledge acquisition, we followed the open-innovation literature and differentiated between transactional and collaborative types of relationships with external knowledge sources (Greco et al., 2016). Our findings suggested that, while mineral companies generally take advantage of both of these mechanisms, choosing one or the other depends on the complexity and tacitness of the knowledge, so that high complexity and/or high tacitness are conducive to the use of more collaborative mechanisms. As proposed by Lane et al. (2006), these two knowledge characteristics are important factors as they explain the ease of gaining access to the external knowledge bases. In this regard, while tacitness depicts the extent to which the knowledge can be codified and transferred, complexity refers to how unknown (in terms of a technology or market) a form of knowledge is for a company.

In the case of technical knowledge where suppliers are the major source, the knowledge flow seems to be primarily one-way (towards the mineral companies), unless the suppliers' existing technical solutions and services do not meet the process requirements. In these complex (technological) situations, mineral companies contribute to the production of new knowledge (e.g. washing equipment) by means of providing information and the opportunity to test the equipment in a real operating environment (Lager et al., 2015). Similarly, with regard to scientific and market knowledge, transactional mechanisms have been found to be more prevalent, as collaborations designed to develop these types of knowledge - which are often far beyond a mineral company's knowledge base - could disperse internal resources and have a detrimental effect on the innovation outcomes (Greco et al., 2016). With respect to social knowledge, tacitness plays an important role in motivating the mineral companies to collaborate with their societal stakeholders. Knowledge about social issues and the expectations of locals could not be codified as it involves individuals' perceptions about the impacts of a company (Hall et al., 2003; Suopajärvi et al., 2016). Thus, mutual interactions are necessary for building trust-based relationships, which in turn result in shared understandings about social issues and the expectations of local communities regarding the minerals industry.

For recognizing (understanding) the external knowledge, our data corroborate the importance of prior knowledge within a company for building absorptive capacity (Cohen and Levinthal, 1990). Contrary to the traditional approaches to innovation, SOI necessitates a broader range of prior knowledge regarding technical, scientific and market aspects, as well as a desire by managers to participate in knowledgeexchange processes with societal stakeholders (Sharma, 2005). Moreover, while prior knowledge and a desire by managers to act ethically 
represent static capabilities (i.e. resources), we argue that successful recognition requires dynamic capabilities, such as new recruitment and training, that assist mineral companies to keep abreast of changes in technologies and markets. In his seminal paper, Teece (2007) suggests that rapid changes in the business environment call for continuous modifications to a company's knowledge base. Accordingly, in line with Lozano (2015), our findings indicate that sustainability transition implies rapid changes in technologies, market demands, environmental regulations and social expectations, thereby highlighting the importance of continuous learning through organizational routines such as employee training that consequently increase a company's ability to understand the external knowledge.

Our case study provides supporting evidence for the importance of internal knowledge dissemination as a capability for the assimilation (integration) of external knowledge. The existing literature on absorptive capacity argues that formal and informal mechanisms of knowledge exchange within a company facilitate knowledge dissemination by means of closing the cognitive gap among the employees (Vega-Jurado et al., 2008; Zahra and George, 2002). As formal mechanisms such as using knowledge-exchange coordinators and job rotation have yet to be developed in the Norwegian minerals industry, internal knowledge dissemination hinges on informal peer-to-peer interactions. We further contributed to the existing literature by demonstrating the interrelatedness between the assimilation of different knowledge types in sustainability contexts. While successful integration of technical and scientific knowledge entails interactions between a relatively limited number of employees (mostly those involved in production), combining external market knowledge involves a knowledge exchange between those in charge of production and marketing activities. These crossfunctional interactions become even broader in the case of social knowledge (Murphy et al., 2012) which, according to our findings, is of a different 'language' and its further application in innovative activities demands the contribution of several functions within a firm.

Finally, this paper proposes that the exploitation of external knowledge in sustainability contexts rests on appropriate capabilities for testing and piloting innovative, new solutions, regardless of their type (product, process or socially oriented practices). This finding contributes to the debate on the importance of considering commercial and non-commercial interests in SOI processes (Amui et al., 2017; Watson et al., 2017) by showing that long-lasting external linkages with societal stakeholders and customers can create mutual value for both the focal company and its collaborators. As a fundamental capability in such linkages, piloting innovative solutions provides significant feedback to a mineral company, enabling it to align its ultimate solution with the needs of customers and/or societal stakeholders (Murphy et al., 2012).

\subsection{Implications for managers and policymakers}

Considering the three outcomes of SOI, policymakers and managers should get involved in efforts that go beyond the frequent focus of the minerals industry on process improvements and economic sustainability. Specifically, pursuing a social innovation path to tackle broader sustainability issues calls for policy interventions that aim to increase awareness about social issues (van der Have and Rubalcaba, 2016). Taking a capability perspective, these policies should be directed towards establishing a range of mechanisms for public engagement, from formal acts such as regulations concerning the involvement of minority groups to informal forums for dialogue between the companies, locals and interest organizations. In this regard, the existence of performance evaluation frameworks such as Towards Sustainable Mining in Canada or Finland is crucial in providing key indicators for measuring the effect of social linkages.

Owing to the financial and human resource limitations of individual mineral companies, strengthening industrial clusters and professional associations should be placed at the core of policy support tools to bring together various companies and external knowledge sources. Although the role of innovation intermediaries has rarely been discussed in the context of non-high-tech industries, recent research suggests that these organizations could help companies in the implementation of open innovation by reducing misunderstandings between managers and creating an arena for discussions among the industrial actors, governmental agencies and societal stakeholders (Radnejad et al., 2017). While the intermediary organizations in the Norwegian minerals industry are primarily focusing on forging external links with suppliers and universities, engaging governmental agencies such as Innovation Norway $^{5}$ could offer funding and network opportunities to promote links with potential markets for raw materials. Moreover, industrial clusters and associations could act as neutral organizations between the mineral companies and societal stakeholders (e.g. NGOs) by involving the latter in knowledge-exchange arenas regarding social issues.

As for building the absorptive capacity for SOI, managers should extend their organizational capabilities beyond the recognition component, in order to take full advantage of external knowledge. In this regard, firstly, more effort is required to assimilate technical, market and social knowledge that often resides in various functions or individuals within a firm, and which consequently hinders its application in addressing broader sustainability issues via innovative activities (Watson et al., 2017). Accordingly, companies need to combine informal and formal mechanisms for internal knowledge dissemination to respond to the challenge of integrating various types of knowledge into their existing knowledge bases. Secondly, our findings signify the necessity of ongoing external linkages even in the knowledge-application step, in the sense that the new products or practices (as outcomes of the exploitation of new knowledge for innovation) meet the expectations of both the company and its stakeholders. As proposed by Watson et al. (2017), this mutual understanding is particularly important for accommodating varying expectations when economic sustainability runs counter to environmental and social sustainability.

We reiterate that addressing sustainability objectives via innovation is a demanding goal that implies the accumulation of a broad range of capabilities and the efficient functioning of various external linkages. Therefore, policymakers and managers should maintain a balance between policies and strategies for building the four types of capabilities by taking into account the types of innovation outcome and the different components of absorptive capacity.

\subsection{Conclusion and future research}

To conclude, we believe that this study sheds some light on the determinants of absorptive capacity for innovations aimed at sustainability. By building on the extant literature and a rich empirical insight from the Norwegian minerals industry, we demonstrated how mineral companies can build appropriate capabilities concerning the different components of absorptive capacity, i.e. recognition, assimilation and exploitation. While some skills and routines for building these capabilities exist, more effort is needed to increase understanding about the various types of knowledge relevant to sustainability contexts. More importantly, company-level strategies and national policies should address the issue of strengthening the ability of firms to integrate and apply external knowledge, with the aim of fulfilling different sustainability objectives.

Nevertheless, this study has some limitations. The first concerns the generalizability of the findings to other industrial settings that differ in character from Norway's minerals industry. Therefore, we call for future studies in other resource-intensive industries and national contexts, possibly in countries with dissimilar market and innovation characteristics. In doing so, taking a longitudinal approach is highly preferential as it will allow researchers to examine how these

\footnotetext{
${ }^{5}$ http://www.innovasjonnorge.no/en/start-page.
} 
capabilities and their underlying routines change over a period of time when firms/industries move through different SOI paths. Second, our approach using qualitative data does not allow for an objective measure of innovation outcomes and of how our interviewees differentiated between incremental and radical innovations. To extend the theoretical understanding, research could employ a quantitative design and use survey-based data to test our arguments. Despite these limitations, we believe that our work makes theoretical and practical contributions to the topic of sustainability in the minerals industry, and could serve as a springboard for future investigations.

\section{Appendix A. Interview protocol for the study}

Interviewee:

Date and time: ...........................

Pre-interview comments:

\section{Introduction}

To facilitate our note-taking, I would like to record our conversation. For your information, only researchers on the project will be privy to the recorded interviews, which will be eventually deleted after they are transcribed.

We have planned this interview to last no longer than one hour. During this time, we have several questions that we would like to cover. If time begins to run short, it may be necessary to interrupt you in order to push ahead and complete this line of questioning. Besides these questions, our line of discussion might raise some extra questions and comments.

You have been invited to participate in this research because you have been identified as someone who has a great deal to share about innovation, knowledge exchange and capability building in the minerals industry. This PhD research project as a whole focuses on the improvement of innovation performance in the industry, with particular interest in understanding how the flow of knowledge and relevant capabilities contribute to that performance. Our study does not aim to evaluate your company's activities or your own experiences. Rather, we are trying to learn more about innovation process, and internal and external practices that are important in this regard.

Interview questions

1. Could you please tell me about the main challenges of your company regarding innovation?

2. How do you deal with these challenges?

3. What are the main opportunities in your business?

4. How can these opportunities be maximized and result in value creation?

5. How does innovation help your company to deal with the challenges and opportunities?

6. Please describe the innovation process in your company.

7. Who are mostly involved in the innovation activities of your company? Both in terms of business units and organizational levels.

8. Please briefly describe how you look for knowledge outside your company.

9. What kinds of practices do you use for bringing in the external knowledge?

10. For which purposes do you use external knowledge in your activities?

11. Could you give me an example of a successful collaboration and a failure example?

12. In your company, what are the internal resources and skills required to do innovation?

13. What motives or purposes are pivotal when you want to choose an external knowledge source?

14. Are there any particular characteristics regarding the type of knowledge you use in your different innovation activities?

15. What are the main knowledge exchange arenas in this industry in Norway?

16. Please briefly describe how knowledge flow happens in those arenas.

Post-interview comments:

Appendix B. From second-order themes to ultimate constructs
External sources of knowledge

- Suppliers (105)

- Research organizations (92)

- Society/NGOs (47)

- Customers (59)

Knowledge acquisition mechanisms

- Collaborative relationship (57)

- Transactional relationship (54)

Type of knowledge required for SOI

- Technical know-how (65)

- Market knowledge (37)

- Scientific knowledge (52)

- Social knowledge (35)

Geographical breadth of linkage

- Local linkage (40)

- National linkage (35)

- International linkage (42)

*The numbers show how many times the second-order themes were mentioned by the interviewees. 
First-order concepts

Second-order

Ultimate

themes

constructs

\begin{tabular}{l}
\hline - The exogenous pressure for local procurement \\
- Region-specific minerals \\
\hline \hline - The culture of trust and openness in Norway \\
- National arenas for knowledge exchange \\
- Global actors in the minerals industry \\
- Product specialization calls for global approach \\
$\begin{array}{l}\text { - The complexity of knowledge in the industry } \\
\text { - Partnerships for specific innovative projects } \\
\text { - Resource barriers to high-level contribution }\end{array}$
\end{tabular}

Appendix C. Demographic overview of the interviewees

\begin{tabular}{llll}
\hline Company & Sector & Interviewee's position & Date of interview \\
\hline $\mathbf{A}$ & Natural and dimension stone & Sales manager & 15.12 .2015 \\
$\mathbf{B}$ & Metallic ores & CEO & 18.12 .2015 \\
$\mathbf{C}$ & Construction minerals & CEO & 21.12 .2015 \\
$\mathbf{D}$ & Metallic ores & CEO & 11.01 .2016 \\
$\mathbf{E}$ & Construction minerals & Production manager & 19.01 .2016 \\
$\mathbf{F}$ & Construction minerals & CEO & 16.02 .2016 \\
$\mathbf{G}$ & Industrial minerals & CEO & 18.02 .2016 \\
$\mathbf{H}$ & Industrial minerals & CEO & 09.03 .2016 \\
$\mathbf{I}$ & Construction minerals & Regional manager & 10.03 .2016 \\
$\mathbf{J}$ & Industrial minerals & R\&D manager & 06.04 .2016 \\
$\mathbf{K}$ & Construction minerals & Production manager & 07.04 .2016 \\
$\mathbf{L}$ & Natural and dimension stone & CEO & 08.04 .2016 \\
$\mathbf{M}$ & Natural and dimension stone & Business development manager & 21.04 .2016 \\
$\mathbf{N}$ & Metallic ores & Chief commercial officer & 03.05 .2016 \\
$\mathbf{O}$ & Industrial minerals & Process development manager & 06.05 .2016 \\
$\mathbf{P}$ & Industrial minerals & CEO & 11.05 .2016 \\
\hline
\end{tabular}

\section{References}

Adams, R., Jeanrenaud, S., Bessant, J., Denyer, D., Overy, P., 2016. Sustainability-oriented Innovation: a systematic review. Int. J. Manag. Rev. 18 (2), 180-205. https:// doi.org/10.1111/ijmr.12068.

Albort-Morant, G., Leal-Millán, A., Cepeda-Carrión, G., 2016. The antecedents of green innovation performance: a model of learning and capabilities. J. Bus. Res. 69 (11), 4912-4917. https://doi.org/10.1016/j.jbusres.2016.04.052.

Amui, L.B.L., Jabbour, C.J.C., de Sousa Jabbour, A.B.L., Kannan, D., 2017. Sustainability as a dynamic organizational capability: a systematic review and a future agenda toward a sustainable transition. J. Clean. Prod. 142 (Part 1), 308-322. https://doi. org/10.1016/j.jclepro.2016.07.103.

Andersen, A.D., Johnson, B.H., Marín, A., Kaplan, D., Stubrin, L, Lundvall, B.-. A., Kaplinsky, R., 2015. Natural resources, innovation and development: Aalborg Universitetsforlag.

Asheim, B.T., Gertler, M.S., 2005. The geography of innovation: regional innovation systems. In: Fagerberg, J., Mowery, D.C., Nelson, R.R. (Eds.), The Oxford Handbook of Innovation. Oxford University Press, Oxford.

Ayuso, S., Rodríguez, M.Á., Ricart, J.E., 2006. Using stakeholder dialogue as a source for new ideas: a dynamic capability underlying sustainable innovation. Corp. Gov.: Int. J. Bus. Soc. 6 (4), 475-490. https://doi.org/10.1108/14720700610689586.

Bartos, P.J., 2007. Is mining a high-tech industry? Investigations into innovation and productivity advance. Resour. Policy 32 (4), 149-158. https://doi.org/10.1016/j. resourpol.2007.07.001.

Bocken, N.M.P., Short, S.W., Rana, P., Evans, S., 2014. A literature and practice review to develop sustainable business model archetypes. J. Clean. Prod. 65, 42-56. https:// doi.org/10.1016/j.jclepro.2013.11.039.

Bogers, M., Lhuillery, S., 2011. A functional perspective on learning and innovation: investigating the organization of absorptive capacity. Ind. Innov. 18 (6), 581-610. https://doi.org/10.1080/13662716.2011.591972.

Ceccaroli, B., Tronstad, R., 2016. Elkem solar and the Norwegian PV industry through 40 Years (1975-2015). In: Ceccaroli, B., Ovrelid, E., Pizzini, S. (Eds.), Solar Silicon Processes: Technologies, Challenges, and Opportunities. CRC Press, Boca Raton.
Chen, S.-H., 2016. The influencing factors of enterprise sustainable innovation: an empirical study. Sustainability 8 (5), 425.

Chesbrough, H., 2003. Open Innovation: The New Imperative for Creating and Profiting from Technology. Harvard Business School Press, Boston, Mass.

Chesbrough, H., Bogers, M., 2014. Explicating open innovation: clarifying an emerging paradigm for understanding innovation. In: Chesbrough, H., Vanhaverbeke, W., West, J. (Eds.), New Frontiers in Open Innovation. Oxford University Press, New York, United States.

Cohen, W.M., Levinthal, D.A., 1990. Absorptive capacity: a new perspective on learning and innovation. Adm. Sci. Q. 35 (1), 128-152. https://doi.org/10.2307/2393553.

Corder, G.D., 2015. Insights from case studies into sustainable design approaches in the minerals industry. Miner. Eng. 76, 47-57. https://doi.org/10.1016/j.mineng.2014. 12.015 .

Dantas, E., Bell, M., 2009. Latecomer firms and the emergence and development of knowledge networks: the case of Petrobras in Brazil. Res. Policy 38 (5), 829-844. https://doi.org/10.1016/j.respol.2009.01.007.

De Marchi, V., 2012. Environmental innovation and R\&D cooperation: empirical evidence from Spanish manufacturing firms. Res. Policy 41 (3), 614-623. https://doi.org/10. 1016/j.respol.2011.10.002

Deakin, H., Wakefield, K., 2014. Skype interviewing: reflections of two PhD researchers. Qual. Res. 14 (5), 603-616. https://doi.org/10.1177/1468794113488126.

Deloitte, 2016. Innovation, state of play: Mining edition 2015.

Dosi, G., 1988. The nature of the innovative process. In: Dosi, G., Freeman, C., Nelson, R., Silverberg, G., Soete, L. (Eds.), Technical Change and Economic Theory. Pinter Publisher, London, pp. 221-238.

Emmel, N., 2013. Sampling and Choosing Cases in Qualitative Research: A Realis Approach. SAGE Publications, London.

Erzurumlu, S.S., Erzurumlu, Y.O., 2015. Sustainable mining development with community using design thinking and multi-criteria decision analysis. Resour. Policy 46, 6-14. https://doi.org/10.1016/j.resourpol.2014.10.001.

European Commission, 2012. Evaluation of the SME definition.

Fagerberg, J., Mowery, D.C., Verspagen, B., 2009. The evolution of Norway's national innovation system. Sci. Public Policy 36 (6), 431-444. https://doi.org/10.3152/ $030234209 \times 460944$. 
Figueiredo, P.N., Piana, J., 2016. When "one thing (almost) leads to another": a microlevel exploration of learning linkages in Brazil's mining industry. Resour. Policy 49, 405-414. https://doi.org/10.1016/j.resourpol.2016.07.008.

Geological Survey of Norway, 2016. Mineral resources in Norway: potential and strategic importance.

George, G., Schillebeeckx, S.J.D., Liak, T.L., 2015. The management of natural resources: an overview and research agenda. Acad. Manag. J. 58 (6), 1595-1613. https://doi. org/10.5465/amj.2015.4006.

Gioia, D.A., Corley, K.G., Hamilton, A.L., 2013. Seeking qualitative rigor in inductive research. Organ. Res. Methods 16 (1), 15-31. https://doi.org/10.1177/ 1094428112452151.

Greco, M., Grimaldi, M., Cricelli, L., 2016. An analysis of the open innovation effect on firm performance. Eur. Manag. J. 34 (5), 501-516. https://doi.org/10.1016/j.emj. 2016.02.008

Grimpe, C., Fier, H., 2010. Informal university technology transfer: a comparison between the United States and Germany. J. Technol. Transf. 35 (6), 637-650. https://doi.org/ 10.1007/s10961-009-9140-4

Hall, J.K., Vredenburg, H., 2003. The challenges of innovating for sustainable development. MIT Sloan Manag. Rev. 45 (1), 61-68.

Hart, S.L., 1995. A natural-resource-based view of the firm. Acad. Manag. Rev. 20, 986-1014.

Hervas-Oliver, J.-L., Albors-Garrigos, J., Baixauli, J.-J., 2012. Beyond R\&D activities: the determinants of firms' absorptive capacity explaining the access to scientific institutes in low-medium-tech contexts. Econ. Innov. New Technol. 21 (1), 55.

Holmes, S., Smart, P., 2009. Exploring open innovation practice in firm-nonprofit engagements: a corporate social responsibility perspective. RD Manag. 39 (4), 394-409. https://doi.org/10.1111/j.1467-9310.2009.00569.x.

Horbach, J., 2008. Determinants of environmental innovation - new evidence from German panel data sources. Res. Policy 37 (1), 163-173. https://doi.org/10.1016/j. respol.2007.08.006.

Jensen, M.B., Johnson, B., Lorenz, E., Lundvall, B.Å., 2007. Forms of knowledge and modes of innovation. Res. Policy 36 (5), 680-693. https://doi.org/10.1016/j.respol. 2007.01.006

Klewitz, J., Hansen, E.G., 2014. Sustainability-oriented innovation of SMEs: a systematic review. J. Clean. Prod. 65, 57-75. https://doi.org/10.1016/j.jclepro.2013.07.017.

Lager, T., Tano, K., Anastasijevic, N., 2015. Open innovation and open production: a case of a technology supplier/user collaboration in the process industries. Int. J. Innov. Manag. 19 (2). https://doi.org/10.1142/S136391961550022X.

Lane, P., Koka, B., Pathak, S., 2006. The reification of absorptive capacity: a critical review and rejuvenation of the construct. Acad. Manag. Rev. 31, 833-863. https://doi. org/10.5465/AMR.2006.22527456.

Lawson, B., Samson, D., 2001. Developing innovation capability in organisations: a dynamic capabilities approach. Int. J. Innov. Manag. 05 (03), 377-400. https://doi.org/ 10.1142/s1363919601000427.

Lei, Y., Cui, N., Pan, D., 2013. Economic and social effects analysis of mineral development in China and policy implications. Resour. Policy 38 (4), 448-457. https://doi. org/10.1016/j.resourpol.2013.06.005.

Lewin, A.Y., Massini, S., Peeters, C., 2011. Microfoundations of internal and external absorptive capacity routines. Organ. Sci. 22 (1), 81-98. https://doi.org/10.1287/ orsc. 1100.0525.

Lozano, R., 2007. Collaboration as a pathway for sustainability. Sustain. Dev. 15 (6), 370-381. https://doi.org/10.1002/sd.322.

Lozano, R., 2015. A holistic perspective on corporate sustainability drivers. Corp. Social. Responsib. Environ. Manag. 22 (1), 32-44. https://doi.org/10.1002/csr.1325.

Madhok, A., Osegowitsch, T., 2000. The international biotechnology industry: a dynamic capabilities perspective. J. Int. Bus. Stud. 31 (2), 325-335. https://doi.org/10.1057/ palgrave.jibs.8490909.

Milanez, B., de Oliveira, J.A.P., 2013. Innovation for sustainable development in artisanal mining: advances in a cluster of opal mining in Brazil. Resour. Policy 38 (4), 427-434. https://doi.org/10.1016/j.resourpol.2013.07.003.

Ministry of Trade and Industry, 2013. Norway Strategy for the Mineral Industry. (K-0725 E). Oslo, Norway.

Morris, M., Kaplinsky, R., Kaplan, D., 2012. "One thing leads to another"-commodities, linkages and industrial development. Resour. Policy 37 (4), 408-416. https://doi. org/10.1016/j.resourpol.2012.06.008.

Murphy, M., Perrot, F., Rivera-Santos, M., 2012. New perspectives on learning and innovation in cross-sector collaborations. J. Bus. Res. 65 (12), 1700-1709. https://doi. org/10.1016/j.jbusres.2012.02.011.

Nidumolu, R., Prahalad, C.K., Rangaswami, M.R., 2009. Why sustainability is now the key driver of innovation. Harv. Bus. Rev. 87 (9), 56-64.

OECD, 2011a. Fostering Innovation for Green Growth. OECD Publishing.

OECD, 2011b. Towards Green Growth. OECD Publishing.

Onkila, T., 2011. Multiple forms of stakeholder interaction in environmental management: business arguments regarding differences in stakeholder relationships. Bus.
Strategy Environ. 20 (6), 379-393. https://doi.org/10.1002/bse.693.

Pavitt, K., 1984. Sectoral patterns of technical change: towards a taxonomy and a theory. Res. Policy 13 (6), 343-373. https://doi.org/10.1016/0048-7333(84)90018-0.

Pratt, M.G., 2009. From the editors: for the lack of a Boilerplate: tips on writing up (and reviewing) qualitative research. Acad. Manag. J. 52 (5), 856-862. https://doi.org/ 10.5465/amj.2009.44632557.

Prno, J., Scott Slocombe, D., 2012. Exploring the origins of 'social license to operate' in the mining sector: perspectives from governance and sustainability theories. Resour. Policy 37 (3), 346-357. https://doi.org/10.1016/j.resourpol.2012.04.002.

Pujari, D., 2006. Eco-innovation and new product development: understanding the in fluences on market performance. Technovation 26 (1), 76-85. https://doi.org/10. 1016/j.technovation.2004.07.006.

Radnejad, A.B., Vredenburg, H., Woiceshyn, J., 2017. Meta-organizing for open innovation under environmental and social pressures in the oil industry. Technovation 66-67, 14-27. https://doi.org/10.1016/j.technovation.2017.01.002.

Robertson, P.L., Casali, G.L., Jacobson, D., 2012. Managing open incremental process innovation: absorptive capacity and distributed learning. Res. Policy 41 (5), 822-832. https://doi.org/10.1016/j.respol.2012.02.008.

Rothaermel, F.T., Hess, A.M., 2007. Building dynamic capabilities: innovation driven by individual-, firm-, and network-level effects. Organ. Sci. 18 (6), 898-921.

Sharma, S., 2005. Through the lens of managerial interpretations: stakeholder engagement, organizational knowledge and innovation. In: Sharma, S., Aragón-Correa, J.A. (Eds.), Corporate Environmental Strategy and Competitive Advantage. Edward Elgar Publishing, Cheltenham, UK, pp. 49-70.

Siggelkow, N., 2007. Persuasion with case studies. Acad. Manag. J. 50 (1), 20-24. https:// doi.org $/ 10.2307 / 20159838$.

Smeds, L., Berlina, A., Jungsberg, L., Mikkola, N., Rasmussen, R.O., Karlsdóttir, A., 2016. Sustainable Business Development in the Nordic Arctic: Nordic Centre for Spatial Development.

Smith, A., Voß, J.-P., Grin, J., 2010. Innovation studies and sustainability transitions: the allure of the multi-level perspective and its challenges. Res. Policy 39 (4), 435-448. https://doi.org/10.1016/j.respol.2010.01.023.

Song, C., Oh, W., 2015. Determinants of innovation in energy intensive industry and implications for energy policy. Energy Policy 81, 122-130. https://doi.org/10.1016/ j.enpol.2015.02.022.

Suopajärvi, L., Poelzer, G.A., Ejdemo, T., Klyuchnikova, E., Korchak, E., Nygaard, V., 2016. Social sustainability in northern mining communities: a study of the European North and Northwest Russia. Resour. Policy 47, 61-68. https://doi.org/10.1016/j. resourpol.2015.11.004.

Teece, D.J., 2007. Explicating dynamic capabilities: the nature and microfoundations of (sustainable) enterprise performance. Strateg. Manag. J. 28 (13), 1319-1350. https://doi.org/10.1002/smj.640.

The Science Park in Bodø, 2017. Mineralnæringens bidrag til nasjonal verdiskaping.

Todorova, G., Durisin, B., 2007. Absorptive capacity: valuing a reconceptualization. Acad. Manag. Rev. 32 (3), 774-786. https://doi.org/10.2307/20159334.

Upstill, G., Hall, P., 2006. Innovation in the minerals industry: Australia in a global context. Resour. Policy 31 (3), 137-145. https://doi.org/10.1016/j.resourpol.2006. 12.002 .

van der Have, R.P., Rubalcaba, L., 2016. Social innovation research: an emerging area of innovation studies? Res. Policy 45 (9), 1923-1935. https://doi.org/10.1016/j.respol. 2016.06.010.

Vega-Jurado, J., Gutiérrez-Gracia, A., Fernández-de-Lucio, I., 2008. Analyzing the determinants of firm's absorptive capacity: beyond R\&D. R\&D Manag. 38 (4), 392-405. https://doi.org/10.1111/j.1467-9310.2008.00525.x.

Veldhuizen, M., Blok, V., Dentoni, D., 2013. Organisational drivers of capabilities for multi-stakeholder dialogue and knowledge integration. J. Chain Netw. Sci. 13 (2), 107-117. https://doi.org/10.3920/jcns2013.1002.

Waller, D., 2014. Mining and Innovation; a fresh approach. Paper presented at the 3DEXPERIENCE Forum, Las Vegas, USA.

Wang, X.B., Yao, M.T., Li, J.S., Zhang, K.X., Zhu, H., Zheng, M.S., 2017. China's rare earths production forecasting and sustainable development policy implications. Sustainability 9 (6). https://doi.org/10.3390/su9061003.

Watson, R., Wilson, H.N., Smart, P., Macdonald, E.K., 2017. Harnessing difference: a capability-based framework for stakeholder engagement in environmental innovation. J. Product. Innov. Manag. https://doi.org/10.1111/jpim.12394.

Westergren, U.H., Holmström, J., 2012. Exploring preconditions for open innovation: value networks in industrial firms. Inf. Organ. 22 (4), 209-226.

Yin, R.K., 2009. Case Study Research: Design and Methods, 4 ed. Sage, Thousand Oaks, Calif.

Zahra, S.A., George, G., 2002. Absorptive capacity: a review, reconceptualization, and extension. Acad. Manag. Rev. 27 (2), 185.

Zollo, M., Winter, S.G., 2002. Deliberate learning and the evolution of dynamic capabilities. Organ. Sci. 13 (3), 339-351. 